\title{
C-Type Lectin Receptors in Antiviral Immunity and Viral Escape
}

\author{
Marta Bermejo-Jambrina ${ }^{1,2 \dagger}$, Julia Eder ${ }^{1 \dagger}$, Leanne C. Helgers ${ }^{1 \dagger}$, Nina Hertoghs ${ }^{1 \dagger}$, \\ Bernadien M. Nijmeijer ${ }^{1 \dagger}$, Melissa Stunnenberg ${ }^{1 \dagger}$ and Teunis B. H. Geijtenbeek ${ }^{1 *}$
}

'Department of Experimental Immunology, Amsterdam Infection and Immunity Institute, Academic Medical Center, University of Amsterdam, Amsterdam, Netherlands, ${ }^{2}$ Division of Hygiene and Medical Microbiology, Medical University of Innsbruck, Innsbruck, Austria

C-type lectin receptors (CLRs) are important pattern recognition receptors involved in recognition and induction of adaptive immunity to pathogens. Certain CLRs play an important role in viral infections as they efficiently interact with viruses. However, it has become clear that deadly viruses subvert the function of CLRs to escape antiviral immunity and promote infection. In particular, viruses target CLRs to suppress or modulate type I interferons that play a central role in the innate and adaptive defense against viruses. In this review, we discuss the function of CLRs in binding to enveloped viruses like HIV-1 and Dengue virus, and how uptake and signaling cascades have decisive effects on the outcome of infection.

Keywords: C-type lectin receptors, antiviral immunity, antigen presentation, type I IFN, complement opsonized HIV-1

\section{INTRODUCTION}

Mucosa and skin are targets for invading viruses and are therefore important sites where adaptive immunity is initiated. Dendritic cells (DCs) and macrophages guard these tissues and detect the invading pathogens by pattern recognition receptors (PRRs) and lead to initiation of immunity and elimination of the pathogens (Figure 1). DCs are professional antigen presenting cells (APCs) that capture pathogens for degradation and antigen presentation, whereas macrophages are a first line of defense that destroy pathogens via degradation but are also able to activate memory T cells (1-3). PRRs are crucial for these functions of DCs and macrophages, as PRRs recognize conserved molecular structures to distinguish between the different types of pathogens, called pathogen-associated molecular patterns (PAMPs) (4). Distinct classes of PRRs recognize a wide range of PAMPs and induce different transcriptional programs leading to tailored immune responses. Furthermore, pathogens will often trigger several PRRs, leading to crosstalk between these receptors, which provide immune cells with another important level of control to tailor the adaptive immune response to the pathogen. Several classes of PRRs exist, such as Toll-like receptors (TLRs), Rig-I-like receptors (RLRs), and C-type lectin receptors (CLRs). Here, we will focus on CLRs that recognize carbohydrate structures, which are able to independently induce immunity or provide powerful signals via crosstalk to modulate responses that are triggered by other PRRs (5). As the immune system is in a never-ending arms race with viruses, many viruses have devised strategies to evade recognition and antiviral immune responses to successfully infect the host. In this review, we describe the complex role of CLRs in the immune processes that are essential in the defense against viruses. In addition, we discuss how certain viruses target specific CLRs to suppress or avoid antiviral immunity. 


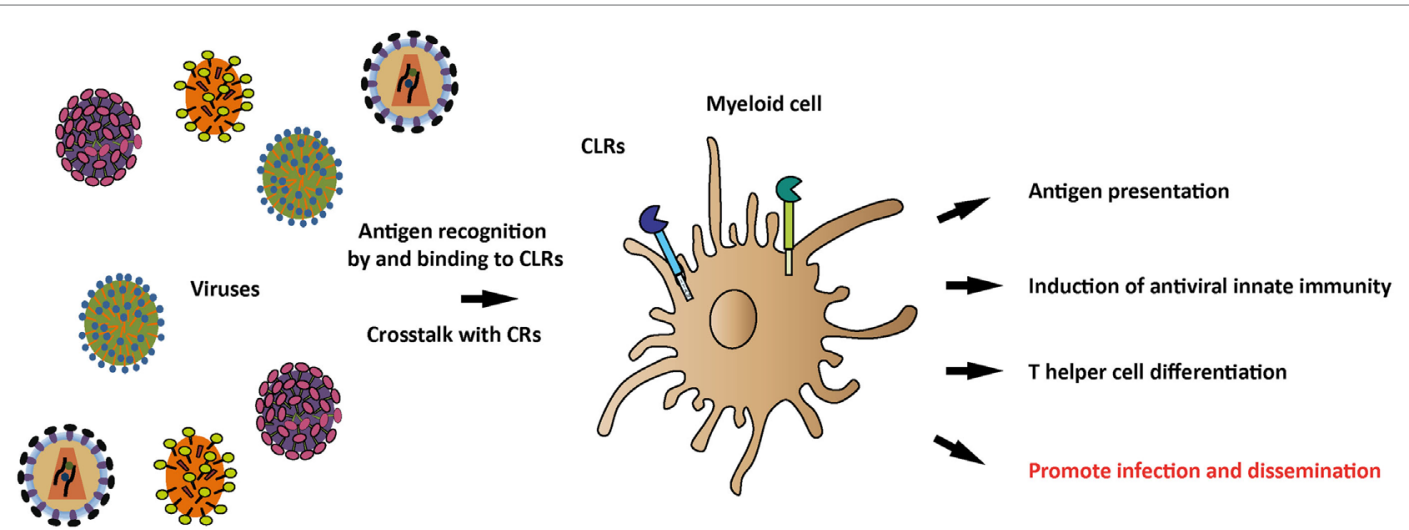

FIGURE 1 | Recognition of viral antigens by C-type lectin receptors (CLRs) and induction of antiviral immune responses. Various CLRs on antigen-presenting myeloid cells recognize a plethora of viruses through their carbohydrate-recognition domains (CRDs) and subsequently induce a tailored immune response, depending on the specific CLR and viral antigens. Viral antigens that trigger the CLR can modulate myeloid cell functions, thereby affecting antigen presentation, antiviral innate immune responses, and T helper differentiation. Once viral antigens are recognized by CLRs, crosstalk between CLRs and complement receptors (CRs) can occur, thereby further shaping the antiviral immune response. Additionally, CLRs play a role in viral recognition, internalization, and dissemination.

\section{CLRs INTERACT WITH VIRUSES, LEADING TO VIRUS DEGRADATION OR TRANSMISSION}

\section{Virus Recognition}

Innate immune cells like monocytes, macrophages, DCs, and Langerhans cells (LCs) express CLRs that act as PRRs. Most of these CLRs bind carbohydrate moieties in a calcium-dependent manner using conserved carbohydrate recognition domains (CRDs) (Figure 2). CLRs are important for recognition and capture of pathogens as these PRRs have a high affinity for their ligands, which results in internalization of the pathogens. Internalization often leads to degradation via lysosomes, which has been shown for the DC-specific ICAM-3 grabbing non-integrin (DC-SIGN; CD209) and DEC-205 (6, 7), or the binding induces degradation via autophagy as shown recently for langerin (8). Therefore, the outcome of CLR recognition depends on the specific CLR and the cell type on which it is expressed.

\section{Lysosomal Degradation and Virus Transmission}

After binding of pathogens by CLRs, the routing (intracellular transport) of antigen has various outcomes depending on the CLR and the immune cell. The Mannose Receptor (MR) is expressed by macrophages and DCs, and is involved in antigen processing and presentation. MR recognizes mannose, $N$-acetylglucosamine, and fucose that are often found on the surfaces of viruses, bacteria, and parasites (9). Upon binding, the pathogen is internalized and targeted to lysosomes for degradation. Subsequently, MR recycles back to the cell surface, for the next round of internalization, resulting in high amounts of internalized pathogens (10). However, several studies have shown that viruses such as HIV-1 and Dengue virus (DENV) target $\mathrm{MR}$ to evade degradation (11). Besides MR, the CLR DC-SIGN also plays an important role in virus binding and internalization. DC-SIGN recognizes mannose and fucose structures (12-14). HIV-1 internalization within DCs is dependent on the association between gp120 and DC-SIGN and this interaction can deliver HIV-1 to lysosomes where they are degraded (6). However, strikingly, a major part of DC-associated HIV-1 evades the degradation pathway by trafficking to a tetraspanin (CD81)-enriched protective environment from where infectious particles are specifically released to T lymphocytes upon DC-T cell contact (15). Thus, a virus that is taken up by DCs can enter two pathways: either routed to the endocytic pathway, resulting in viral degradation and antigen presentation or diverted to a transmission pathway and thereby avoids degradation. It is unknown how these pathways are related and which factors determine the fate of the virus. Langerin is a CLR expressed exclusively on LCs and is important for antigen capture and internalization, which induces Birbeck granules (BG) formation and routing of antigen into organelles (16). Langerin has a role in antiviral protection as immature LCs capture HIV-1 via langerin, leading to TRIM $5 \alpha$-mediated autophagic degradation of HIV-1, which prevents LC infection $(8,17)$. Thus, CLRs are important in the final fate of the virus, which can be either routing for degradation or dissemination.

\section{Antigen Presentation}

Next to routing of antigen in lysosomal pathways for degradation, antigen presentation on major histocompatibility complex (MHC) molecules is an important anti-viral immune mechanism. Many antigens taken up by various CLRs such as DC-SIGN, DEC-205, DCIR, or dectin-1 are routed into MHC class II compartments, where the antigens are loaded for presentation to CD $4+\mathrm{T}$ cells (18-21). These MHC class II molecules are released from late endocytic compartments and accumulate at the cell surface (22). The expression of most CLRs is generally downregulated upon cell maturation (23). Mature DCs have a reduced capacity to take up antigen, which is reflected by lower levels of CLRs, but are more efficient in stimulating $\mathrm{T}$ cells through stabilizing $\mathrm{MHC}$ class I and class II at the cell surface (24). An exception represents 


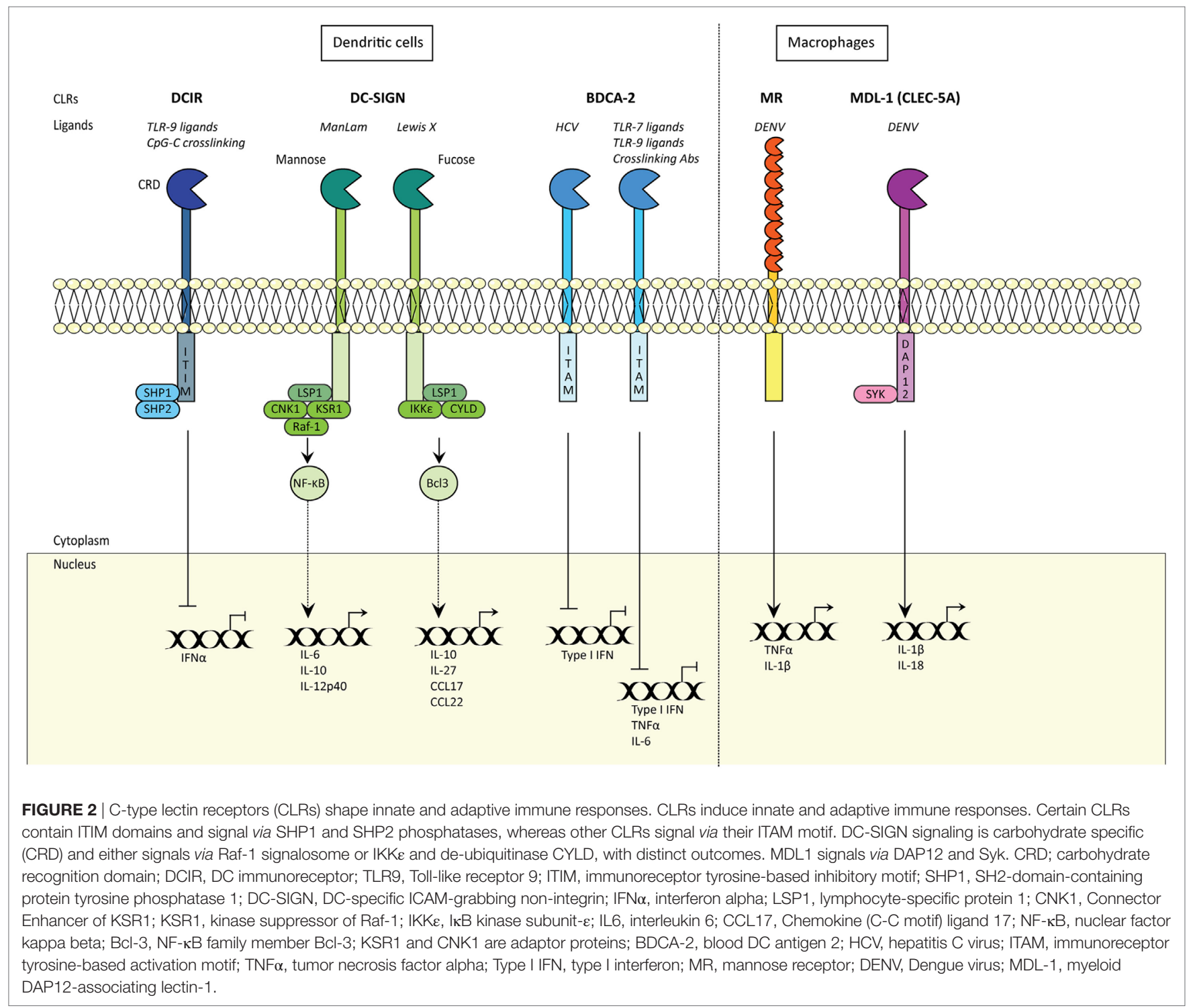

DEC-205, as the receptor is upregulated in mature plasmacytoid DCs (pDCs) (25). Importantly, antigen presentation by DEC-205 is not affected by this as endocytosis of an antigen targeted to DEC-205 via an antibody still leads to antigen presentation and CD4 + T cell induction in immature as well as activated pDCs (25). Furthermore, CLR Siglec-1 is upregulated upon DC maturation (26). It is unclear whether this affects antigen presentation, but the enhanced expression of Siglec-1 enhances HIV-1 transmission (27). Since CLR internalization enhances antigen presentation, several strategies have been designed to target these CLRs with antibodies or antigens for vaccination purposes.

\section{Virus Transmission}

Virus internalization can lead to antigen presentation but, strikingly, several CLRs have been shown to protect the virus and promote viral transmission and dissemination (15, 28-30). Virus transmission in the context of DCs can be in cis, which depends on productive infection of DCs or in trans, where CLRs function as attachment receptors that facilitate capture and transmission without infection of the DC. DC-SIGN is an important CLR on DCs involved in transmission of viruses to susceptible target cells (15), facilitating virus dissemination throughout the host. After DC-SIGN mediated endocytosis of HIV-1, these virions can be kept in multivesicular bodies to enable the release of HIV associated with exosomes. This trans-infection pathway in DCs helps with dissemination of HIV-1 to CD4 + T-cells $(31,32)$. DC-SIGN also interacts with flaviviruses via mannose glycans present on viral envelope glycoproteins and is used by DENV, Hepatitis C virus (HCV) (33), Sindbis virus (34), and the West Nile virus (WNV) for cellular attachment and infection of immature DCs $(35,36)$. Studies have shown that HCV particles bind to DC-SIGN and are targeted to non-lysosomal compartments in immature DCs, where they are protected from lysosomal degradation and transmit the virus to hepatocytes (33). DC-SIGN functions as an 
attachment receptor for many different viruses, such as DC-SIGN also mediates Cytomegalovirus (CMV) and Ebola virus (EBOV) enters into DCs and facilitates transmission to susceptible cells in cis and trans $(37,38)$. This function is not exclusive for DC-SIGN. Capture of HIV-1 by MR on macrophages also results in protection of the virus and transmission to T-cells (29). Another CLR involved in virus transmission is DCIR. The DCIR expression was detected on DCs, monocytes, macrophages, B-lymphocytes, and granulocytes (23) such as DC-SIGN, DCIR captures HIV-1 and promotes infection in cis and trans of CD4 + T-cells from immature DCs (28). Inhibiting HIV-1 binding to DCIR on DCs significantly decreases exosomal release of HIV-1 (39), which might be the mechanism for transmission. In contrast, langerin prevents HIV-1 transmission by LCs via autophagosomal degradation of HIV-1 (8). When langerin function is impaired, LCs become infected and subsequently transmit HIV-1 to T cells in cis $(3,9)$. In contrast, langerin also functions as an attachment and an entry receptor for influenza A virus and thereby promotes viral dissemination (40). It is unclear how Influenza A virus escapes autophagosomal degradation by langerin. Thus, several viruses have devised strategies to subvert the internalization route of CLRs in order to promote viral dissemination. It is interesting that even though viruses such as HIV-1 escape from degradation in DCs, these DCs still present HIV-1 derived antigens in the context of MHC-II to CD4 + T cells (41). These data suggest that capture by DCs and simultaneous presentation of antigens to CD4 $+\mathrm{T}$ cells might enhance the destruction of virus-specific $\mathrm{T}$ cells. Moreover, internalization routes of CLRs might be not exclusive for antigen presentation or virus protection, and both routes can occur simultaneously.

\section{Cross-Presentation}

Besides activation of CD4 $+\mathrm{T}$ helper $\left(\mathrm{T}_{\mathrm{H}}\right)$ subsets, CLRs have also been implied in cross-presentation. Via this process, DCs can elicit cytotoxic $\mathrm{T}$ cell responses by presenting exogenous antigens via MHC class I (42). There are at least two pathways that are generally referred to as "cytosolic" and "vacuolar" (42). Upon endocytosis, antigen processing for MHC class I loading either takes place in endocytic compartments or the cytosol (43-45). Several mechanisms are involved in the transfer of antigens from endosomes into the cytosol and include unfolding of proteins, members of the ER-associated degradation machinery like p97 and the pore-building protein Sec61 as has been reviewed by Schuette and Burgdorf (46). "Cross-priming" describes the subsequent stimulation and expansion of naive CD8 $+\mathrm{T}$ cells to initiate cytotoxic immune responses and memory $\mathrm{T}$ cells (47). Even though the exact mechanisms are still under investigation, it is evident that CLRs facilitate uptake that leads to cytosolic exposure and cross-presentation. The BDCA3 + CD141 + DCs excel at cross-presentation and have recently been suggested as the main cross-presenting DC subset in humans, closely resembling mouse CD8 + DCs (48-50). Interestingly, this DC subset expresses CLR CLEC9A (DNGR-1) that efficiently internalizes antigens for cross-presentation (51-53). CLEC9A binds to F-actin (54), which is exposed in necrotic cells and CLEC9A might be involved in cross-presentation of antigens from necrotic cells that have, for example, been infected by viruses. Indeed, murine
CLEC9A-deficient DCs are unable to facilitate cross-presentation of Vaccinia virus antigens upon infection (55). CLEC9A might facilitate not only antigen presentation but also activation of CD8 + T cells by presenting signals of tissue damage (55). Moreover, CLEC9A also promotes cross-presentation of dead cell-associated antigens by altering the route of internalization as CLEC9A co-localizes with the phagocytosed necrotic cargo, which diverts the cargo toward the recycling endosomal route for MHC class I presentation (56). Upon infection with the highly immunogenic Herpes simplex virus, cytotoxic CD8 $+\mathrm{T}$ cell responses were reduced in mice lacking CLEC9A (56). In humans targeting antigens by CLEC9A antibodies to immature BDCA3 + DCs leads to cross-presentation and induction of antigen-specific CD $4+$ and CD8 + T cells, whereas DC maturation and cytokine production are not affected (57). Antigens targeted to DCIR on different DC subsets result in efficient cross-priming and cross-presentation (58). DC-SIGN is also able to route viruses or antigens into the cross-presentation pathway as HIV-1 antigens are presented to MHC class I via DC-SIGN capture $(59,60)$. Upon internalization and processing of HIV-1 via DC-SIGN, viral exogenous antigens are cross-presented on MHC class I, thereby inducing anti-HIV cytotoxic T cell (CTL) responses (6). Interestingly, the group around Moris et al suggests that the virus in this case is not routed toward lysosomes but is processed by another, proteasome-dependent pathway. Whether langerin is capable of inducing cross-presentation is under debate. Internalization of synthetic long peptides through langerin on LCs enhances cross-presentation $(61,62)$. Whereas, activated LCs become infected by measles virus (MV) and therefore present newly formed virions via MHC class I to MV-specific CD8 + T cells (63). Targeting of MV or MV-infected cells to langerin does not result in cross-presentation, suggesting that langerin routing into BG is not linked to the cross-presentation route (63). MR promotes cross-presentation by routing its cargo into a distinct, low degradative, early endosome subset $(7,64)$. Importantly, due to poly-ubiquitination of its cytoplasmic tail (65) as well as recruitment of p97 to the endosomal membrane (66), MR might not only internalize antigens but also export the antigens from the endosomal compartment into the cytoplasm (67). The mechanisms of cross-presentation are currently studied extensively in the context of tumor immunology with CLRs as attractive targets $(62,68,69)$. However, their impact is also crucial for anti-viral immune responses, and their proven and proposed roles during antigen uptake and presentation depict that CLRs have an important role in connecting these processes.

\section{SHAPING ANTIVIRAL INNATE IMMUNE RESPONSES BY CLRS}

PRR signaling in DCs is vital to the induction of innate and adaptive immune responses to viruses. Type I IFN responses are paramount in limiting viral replication and therefore form a strong innate immune defense mechanism against invading viruses (70-73). Moreover, type I IFN responses also modulate adaptive immunity thereby further tailoring immunity to the pathogen. Different CLRs possess the capacity to activate various 
innate signaling pathways that give rise to specific types of cellular immune responses (Figure 2) (74). However, viruses contain the capacity to alter CLR-induced signaling, thereby inhibiting induction of type I IFN responses (75).

\section{Type I IFN Responses in DCs}

Sensing of viral structures via a variety of PRRs induces an antiviral program to help viral infections (76-78). This innate antiviral program consists predominantly of various IFN $\alpha$ subtypes and IFN $\beta$, which has been reviewed extensively elsewhere (79). IFN $\alpha$ and IFN $\beta$ are both produced by DCs, but IFN $\alpha$ is predominantly secreted by pDCs (80-82). Membrane-bound TLRs trigger signaling cascades leading to phosphorylation of interferonregulatory factor 3 (IRF3) and IRF7 activate transcription of IFNA and IFNB genes $(82,83)$. IRF3 and IRF7 are crucial in inducing type I IFN, albeit in a different manner. IRF3 is indispensable for the first production of type I IFN and predominantly activates IFN $\beta$ signaling, which then initiates transcription of IRF7 thereby strongly inducing IFN $\alpha$. IRF7 in contrast to IRF3 is not constitutively expressed by DCs, and is upregulated by IFN signaling. Therefore, IRF7-induced IFN $\alpha$ is under control of IRF3 activation and thus IFN $\beta$ production $(4,78,82,83)$. Therefore, IFN $\beta$ comprises the very first line of antiviral defense as it forms the first wave of type I IFN. Secreted IFN $\alpha / \beta$ proteins bind the heterodimeric transmembrane IFN receptors (IFNARs) on the cell surface (78). Upon receptor ligation, intracellular signaling leads to induction of $I F N A / B$ gene transcription and transcription of interferon stimulated genes (ISGs) Depending on the cell type, IFN dosage and timing of the first wave of IFN exposure, 50-1000 ISG can be identified among 200-500 different cell types (84). ISGs form an important antiviral type I IFN component, since they can interfere with viral replication steps or serve as viral restriction factors (70-73). Thus, upon transcription of $I F N A / B$ genes a self-enhancing antiviral program is induced that can strongly inhibit viral replication. In addition, the production of type I IFN is essential to adaptive immunity as these cytokines control proliferation, differentiation, activation and maturation of monocytes, DCs, and macrophages (85). Therefore, type I IFN plays a crucial role in the induction of antiviral immunity.

\section{Shaping of Innate Immune Responses by CLRs}

C-type lectin receptors are important in inducing and modulating immunity (Figure 2). Some CLRs contain immunoreceptor tyrosine-based activation motifs (ITAMs), hemi-ITAMs, or immunoreceptor tyrosine-based inhibitory motifs (ITIMs), whereas some do not contain any obvious signaling motifs (75). Dectin-2, DCAR, and MDL-1 belong to the ITAM-containing CLRs, whereas DCIR contains an ITIM. Dectin-1 belongs to the hemi-ITAM group, and other CLRs such as DC-SIGN, MR, and DEC-205 do not contain any known ITAMs or ITIMs (75). DCIR is expressed by DCs and macrophages, and contains an ITIM that mediates inhibitory signals by recruiting phosphatases $\mathrm{SH} 2$-domain-containing protein tyrosine phosphatase 1 (SHP1) or SHP2 after receptor ligation (86). Endocytosis of DCIR on DCs does not affect TLR4 and TLR8-dependent DC maturation (87).
However, DCIR inhibits TLR8-dependent IL-12 and TNF $\alpha$ production, whereas TLR2, TLR3, and TLR4-induced cytokine levels are unaffected (87). DCIR is also expressed on macrophages, and its activation inhibits $\mathrm{CpG}-\mathrm{ODN}$-induced expression of proinflammatory cytokines IL-1 $\beta$ and IL-6 (88). Although DCIR inhibits IFN $\alpha$ (19), it also serves an opposing role by sustaining type I IFN responses (89) as murine DCs deficient in DCIR have decreased STAT1 phosphorylation upon Mycobacterium tuberculosis infection, indicating that DCIR sustains STAT1 and therefore type I IFN responses (89). Notably, DCIR expression inhibits IL12p70 production and DC-dependent $\mathrm{T}_{\mathrm{H}} 1$ skewing (89). Thus, DCIR depending on the DC subset can inhibit or sustain type I IFN responses depending on the pathogen and cell-type. Whether DCIR is able to sustain type I IFN responses in humans and against viruses remains elusive. DCIR contributes to DC capture and dissemination of HIV-1, whereas murine DCIR has shown to be involved in the internalization of Chikungunya virus (CHIKV) $(28,90)$. Whether DCIR, in this context, functions as a $\mathrm{PRR}$ and is able to sustain type I IFN responses remains elusive. HIV-1 induces DCIR expression on T cells, which increases viral entry and replication (91) whereas DCIR serves a protective role in CHIKV infection (90). Thus, depending on the virus and on the origin of the host cell, DCIR appears to either protect against or enhance viral infection of the host cell. BDCA-2 (CLEC4C, CD303) is expressed by pDCs and therefore widely used to identify pDCs (92). BDCA-2 inhibits type I IFN responses in pDCs in response to $\mathrm{CpG}$ oligonucleotides, Influenza virus, or DNAautoantibody complexes $(93,94)$. Similar to Dectin-2 and DCAR, BDCA-2 contains the capacity to engage with the transmembrane adaptor FceRI $\gamma$ (95) and induce ITAM-dependent signaling (96). BDCA-2 crosslinking with antibodies on pDCs inhibits both type I IFN and pro-inflammatory cytokine responses after TLR7 and TLR9 triggering (96). Interestingly, BDCA-2 on pDCs interacts with HCV glycoprotein E2, which similarly blocks type I IFN responses (97). MR binding to DENV on macrophages induces pro-inflammatory cytokines TNF $\alpha$ and IL-1 $\beta$, causing decreased endothelial integrity and leading to more severe disease symptoms $(11,98)$. As MR expression is increased during DENV infection via IL-4, this suggests that MR-induced cytokines might be important in sustained high cytokine responses $(99,100)$. Recent findings have shown that when macrophages are stimulated with vitamin D3, IL-4-induced MR upregulation is attenuated and thus leads to decreased ligation of viral particles to macrophages (101). MDL-1 (CLEC-5A) also interacts with DENV and induces Syk-dependent pro-inflammatory IL- $1 \beta$ and IL-18 responses upon DENV-induced inflammation (102). Ligation of MDL-1 activates the NLRP3 inflammasome and pyroptosis (102). In macrophages, MDL-1 is exploited by Japanese encephalitis virus, which uses this inflammatory axis to induce virus-dependent inflammation of host cells (103). Moreover, MDL-1 binding to Influenza A virus $(104,105)$ contributes to Influenza A virus pathogenicity through induction of pro-inflammatory responses in a murine model (105). HIV-1 binding to DC-SIGN induces signaling by DC-SIGN that affects TLR-mediated signaling. Endosomal degradation of HIV-1 triggers TLR8-dependent NF- $\kappa B$ and initiates transcription of integrated HIV-1 $(106,107)$. Notably, DC-SIGN signaling by HIV-1 induces phosphorylation 
of NF- $\mathrm{NB}$ allowing propagation of transcription and production of viral proteins (108). Thus, DC-SIGN-dependent endocytosis and signaling is exploited by HIV-1. Furthermore, a recent study showed that HIV-1 targets DC-SIGN on primary DC subsets to suppress type I IFN responses induced by the HIV-1 sensor DDX3 (109). Similarly, MV exploits DC-SIGN signaling to suppress type I IFN responses as DC-SIGN signaling blocks phosphatases that are crucial in activation of MV-sensors RIG-I and MDA5 (110). Thus, both HIV-1 and MV exploit DC-SIGN signaling to inhibit antiviral type I IFN responses.

\section{CLRs IN T HELPER CELL POLARIZATION}

Efficient pathogen-specific $\mathrm{T}$ cell responses require differentiation of CD4 $+\mathrm{T}$ cells into various $\mathrm{T}_{\mathrm{H}}$ cell subsets (Figure $\mathbf{1}$ ). Distinct $\mathrm{T}_{\mathrm{H}}$ cell subsets each have specialized roles in the defense against invading pathogens. $\mathrm{A} \mathrm{T}_{\mathrm{H}} 1$ response is directed against intracellular pathogens, whereas $\mathrm{T}_{\mathrm{H}} 2$ cells produce IL-4, IL-5, and IL-13 to combat extracellular pathogens (111). Follicular $\mathrm{T}_{\mathrm{H}}$ cells $\left(\mathrm{T}_{\mathrm{FH}}\right)$ are crucial for efficient $\mathrm{B}$ cell responses by the formation of germinal centers in the lymph node. In these germinal centers, $\mathrm{T}_{\mathrm{FH}}$ stimulate $\mathrm{B}$ cell proliferation and isotype class-switching via the production of IL-21 $(112,113)$. CLRs crosstalk with other PRRs to induce specific cytokine expression profiles thereby directing $\mathrm{T}_{\mathrm{H}}$ cell polarization (114). DC-SIGN distinguishes between mannose- and fucose-containing antigens (14, 115, 116). Notably, differential recognition of mannose and fucose structures by DC-SIGN results in the induction of disparate intracellular pathways that are controlled by the composition of the signalosome bound to DC-SIGN $(112,117,118)$. DC-SIGN is continuously bound by adaptor protein LSP1 in combination with a signalosome complex KSR1, CNK, and kinase Raf-1 (Figure 2) (117). Activation of DC-SIGN by mannosecontaining pathogens such as HIV-1 or MV leads to activation of Raf-1. Raf- 1 triggers a signaling pathway that induces a specific phosphorylation of NF- $\kappa \mathrm{B}$, thereby enhancing the transcription of pro-inflammatory cytokines IL-6 and IL-12 (Figure 2) (74, 119). High mannose structures are prevalent on the surface of many viruses including HIV-1, EBOV, HCV, DENV, CMV, and SARS coronavirus (SARS-CoV) (74). Therefore, the interaction of these viruses with DC-SIGN might enhance the induction of $\mathrm{T}_{\mathrm{H}} 1$ responses (120). In contrast, activation of DC-SIGN by fucose-expressing pathogens dissociates the Raf-1 signalosome from LSP1 and recruits IкB kinase subunit- $\varepsilon$ (IKKe) and the de-ubiquitinase (CYLD) (Figure 2) (112, 118). CYLD activation results in accumulation of ubiquitinated $\mathrm{Bcl} 3$ in the nucleus, which forms p50-p50-Bcl3 complexes that inhibit IL-12 production and enhances $\mathrm{T}_{\mathrm{H}} 2$-associated cytokines IL-10, and CCL17 and CCL22 (Figure 2) (118). Indeed fucose-containing pathogens induce $\mathrm{T}_{\mathrm{H}} 2$ polarization via DC-SIGN activation (118). Furthermore, fucose-induced signaling by DC-SIGN also modulates IFNR signaling, which is paramount to the induction of IL-27 and $\mathrm{T}_{\mathrm{FH}}$ cells (112). Mostly parasites express fucose, suggesting that DC-SIGN is important in the defense against parasites that require $\mathrm{T}_{\mathrm{H}} 1$ and $\mathrm{T}_{\mathrm{FH}}$ responses. Interestingly, a few viruses, such as DENV, expose fucose-structures on their surface. However, it remains unclear whether these viral
fucose-DC-SIGN interactions induce $\mathrm{T}_{\mathrm{H}} 2$ responses. It might be possible that other CLRs also induce $\mathrm{T}_{\mathrm{H}} 2$ fucose-dependent differentiation. CLRs such as langerin and MR also interact with LSP1, suggesting that the signaling properties of these receptors are similar to DC-SIGN. Besides DC-SIGN, other receptors are also involved in $\mathrm{T}$ cell polarization. MR is known to inhibit the production of TLR4-induced IL-12 secretion in DCs (121). Among DCs, DCIR and myeloid inhibitory C-type lectin-like receptor (MICL) both down-regulate TLR-induced IL-12 secretion via activation of intracellular ITIM motifs $(87,122)$. In addition, BDCA2 downregulates TLR-mediated IL- 6 production by preventing recruitment of MyD88 to the intracellular domains of TLRs in pDCs (93). Therefore, activation of one or more of these CLRs might skew toward a $\mathrm{T}_{\mathrm{H}} 2$ balance. However, most of these studies used bacterial ligand such as LPS to investigate cytokine response upon CLR stimulation. Additional research is needed to investigate whether these receptors still exhibit these signaling modulating functions upon viral infections.

\section{CROSSTALK BETWEEN CLRS AND COMPLEMENT RECEPTORS (CRs)}

C-type lectin receptors are also involved in complementdependent clearance of pathogens as well as induction of immunity. The complement system can be activated through three distinct pathways, named the classical, the lectin, and the alternative pathway (123). The three different cascades are responsible in activating complement factor $\mathrm{C} 3 \mathrm{~b}$ that deposits on diverse surface formations of pathogens and apoptotic cells inducing opsonization, inflammation, phagocytosis, elimination of the pathogen, and lastly, the induction of adaptive immune responses. Interestingly, the soluble CLR MBL is involved in the lectin pathway and recognizes carbohydrates such as mannose, glucose, L-fucose, $N$-acetyl-mannosamine (ManNAc), and $\mathrm{N}$-acetyl-glucosamine (GlcNAc) on a wide range of pathogens (124). The recognition of carbohydrates is mediated via the CRDs and oligomerization of $\mathrm{MBL}$ enables high avidity binding to repetitive carbohydrate ligands. Once bound, MBL has the capacity to modify the efficiency of uptake by the expression of other phagocytic receptors. MBL further activates complement, due to its association with Mannose-binding lectin-Associated Serine Proteases, or act directly as an opsonin $(125,126)$, which results in deposition of complement on the pathogen surface that leads to uptake via CRs $(126,127)$. MBL has been found to bind directly to virions from a number of different virus families, including HIV, SARS-CoV, EBOV, DENV, and WNV. For instance, MBL binds directly to HIV-infected cells (128) and HIV-1 particles that lack gp120 do not bind MBL, supporting the idea that gp120 and gp41 directly bind to $\mathrm{C} 1 \mathrm{q}$ and guide the interaction between the whole virus and $\mathrm{MBL}(129,130)$. Despite these findings, the role of MBL in HIV pathogenesis is still unclear. Moreover, complement also affects CLR function. When entering the host, complement is spontaneously deposited on the surface of HIV-1 since gp120 and gp41 contain a C1q binding site (131). Over the past years, a lot of studies have supported the idea that HIV-1 envelope glycoprotein gp41 functions as a viral ligand for $\mathrm{gClqR}$ 
(132-135), the receptor for the globular heads of C1q complex, which modulates a plethora of immunological functions, such as infection and inflammation. The HIV-1 transmembrane glycoprotein gp41 has been shown to interact with the C1q complex $(136,137)$, causing the activation of the classical pathway of the complement system (Figure 3). Furthermore, different studies have shown that MBL interacts with HIV-1. Expression of viral proteins, gp120 and gp41, seems to be crucial for the HIV-1-MBL interaction. However, the binding is presumably to the $N$-linked glycans on the gp120 (Figure 3), due to the fact that it is highly glycosylated and in contrast there are only few potential $\mathrm{N}$-linked carbohydrate sites on gp41 $(138,139)$. MBL interaction with the envelope glycoprotein of different HIV-1 strains mediate several downstream antiviral effects, in particular the complement activation, independent of $\mathrm{Clq}$ and antibodies, inducing the lectin pathway and enhancing the opsonization and viral elimination $(128,140)$. Complement is important early in infection, when HIV-1 specific antibodies are still absent. Complement is active at the mucosal site and in the seminal fluid, which suggests that the virus is opsonized with C3b prior to transmission (141).
Opsonization reduces the accessibility of the viral envelope protein gp120, and interferes with the CLR interaction of the virus with DCs (142). In addition, complement opsonization of HIV-1 causes a significantly higher productive infection of DCs, which is caused by binding to the CR3, whereas non-opsonized HIV-1 is bound via gp120 to DC-SIGN (143) (Figure 3). However, complement is a two-edged sword and besides its clearance and neutralization activity, it also enhances viral spread and maintenance. Thus, complement-coated HIV-1 accumulates in different parts of the host and is able to bind CR-expressing immune cells, for example DCs, macrophages, NK cells, B cells, or even follicular DCs, thereby enhancing infectivity and dissemination $(130,144)$. In addition, novel complement activation pathways have been identified such as interaction of C1q with CLR SIGN-R1 expressed on macrophages (145), and cells with a DC-like phenotype (146). It has been widely accepted that infection of DCs by HIV-1 and DC-mediated transmission of the virus to $\mathrm{T}$ cells is mediated by CLRs (143), but this is not the case for opsonized virus. The productive infection caused by HIV-C is associated with an activation of DC responses characterized by up-regulation of

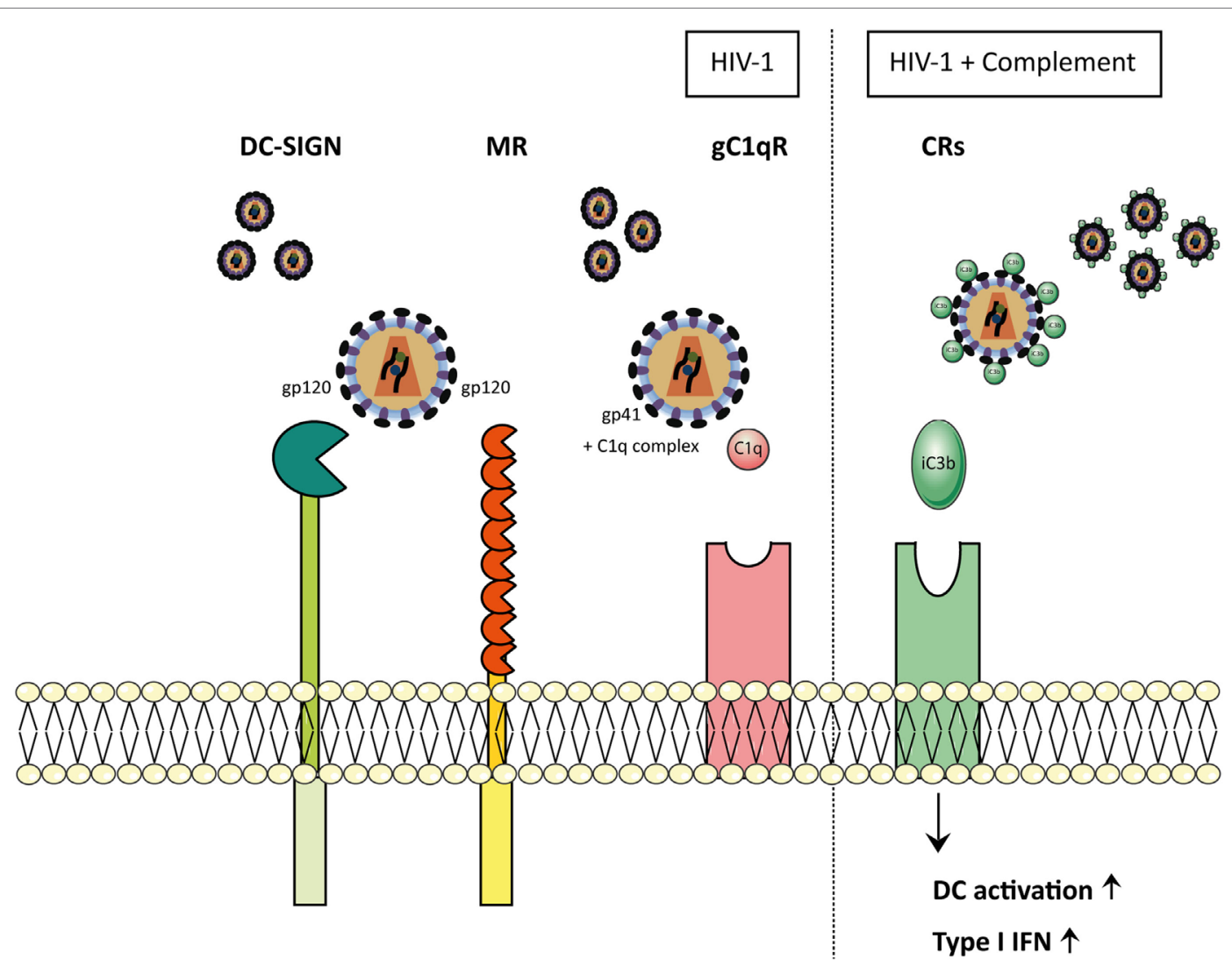

FIGURE 3 | HIV-1 particles opsonize-dependent recognition on myeloid cells. In physiological conditions, when HIV-1 enters the body, it is either non-opsonized (HIV) or complement-opsonized (HIV-C). Depending on the opsonization pattern of the virions, interactions with the receptors differ. Non-opsonized virus (HIV-1) interacts with CLR receptors, such as DC-SIGN and mannose receptor (MR) via the glycoprotein gp120. Furthermore, non-opsonized virus (HIV-1) is able to establish an interaction between gp41 and C1q complex, allowing the final binding to gC1qR. MR and C1qR cause the activation of the complement system via the lectin pathway and the classical pathway, respectively, inducing complement-mediated opsonization of the virions. Once HIV is coated by C3b fragments, it is able to bind to the complement receptors (CRs). Dendritic cells (DCs) exposed to complement-opsonized HIV-1 showed increased activation as well as up-regulation of type I IFNs. 
maturation (CD83, CCR7), co-stimulatory function (CD40 and CD86), together with HLA-DR and HLA-ABC. Furthermore, innate type I IFN responses are enhanced that are also involved in T cell activation (CXCL9, CXCL10, CXCL11), suggesting that there is also an improved antiviral response (147) (Figure 3).

\section{CONCLUDING REMARKS}

Some CLRs are important in shaping innate and adaptive immunity to different viruses. Many viruses interact with CLRs and the elicited immune responses are induced by triggering of CLRs in combination with PRRs. Although the intracellular signaling pathways have not been clearly defined for most CLRs, it is becoming evident that CLRs are very efficient in modulating signaling by other PRRs. This seems to be a recurring feature that is important in tailoring adaptive immunity to the pathogens. However, certain viruses have subverted these CLRs to inhibit antiviral immunity. In particular, several CLRs have been shown to inhibit type I IFN responses, which is crucial for a strong effective antiviral immune response. Moreover, although CLRs are currently main players in immunotherapy strategies to enhance antigen presentation to tumor antigens, the intracellular routing of CLRs is subverted by many viruses for viral transmission. These

\section{REFERENCES}

1. Banchereau J, Steinman RM. Dendritic cells and the control of immunity. Nature (1998) 392:245-52. doi:10.1038/32588

2. Murray PJ, Wynn TA. Protective and pathogenic functions of macrophage subsets. Nat Rev Immunol (2011) 11:723-37. doi:10.1038/nri3073

3. Pozzi L-AM, Maciaszek JW, Rock KL. Both dendritic cells and macrophages can stimulate naive CD8 T cells in vivo to proliferate, develop effector function, and differentiate into memory cells. J Immunol (2005) 175:2071-81. doi:10.4049/JIMMUNOL.175.4.2071

4. Iwasaki A, Medzhitov R. Regulation of adaptative immunity bye the innate immune system. Science (2010) 327:291-5. doi:10.1126/science.1183021. Regulation

5. Zelensky AN, Gready JE. The C-type lectin-like domain superfamily. FEBS J (2005) 272:6179-217. doi:10.1111/j.1742-4658.2005.05031.x

6. Moris A, Nobile C, Buseyne F, Porrot F, Abastado JP, Schwartz O. DC-SIGN promotes exogenous MHC-I-restricted HIV-1 antigen presentation. Blood (2004) 103:2648-54. doi:10.1182/blood-2003-07-2532

7. Chatterjee B, Smed-Sorensen A, Cohn L, Chalouni C, Vandlen R, Lee B-C, et al. Internalization and endosomal degradation of receptor-bound antigens regulate the efficiency of cross presentation by human dendritic cells. Blood (2012) 120:2011-20. doi:10.1182/blood-2012-01-402370

8. Ribeiro CMS, Sarrami-Forooshani R, Setiawan LC, Zijlstra-Willems EM, van Hamme JL, Tigchelaar W, et al. Receptor usage dictates HIV-1 restriction by human TRIM5 $\alpha$ in dendritic cell subsets. Nature (2016) 540:448-52. doi:10.1038/nature20567

9. East L. The mannose receptor family. Biochim Biophys Acta (2002) 1572: 364-86. doi:10.1016/S0304-4165(02)00319-7

10. Sallusto BF, Cella M, Danieli C, Lanzavecchia A. Dendritic cells use macropinocytosis and the mannose receptor to concentrate macromolecules in the MHC class II compartment: downregulation by cytokines and bacterial products. J Exp Med (1995) 182:389-400. doi:10.1084/jem.182. 2.389

11. Miller JL, deWet BJM, Martinez-Pomares L, Radcliffe CM, Dwek RA, Rudd PM, et al. The mannose receptor mediates dengue virus infection of macrophages. PLoS Pathog (2008) 4:e17. doi:10.1371/journal.ppat.0040017

12. Geijtenbeek TBH, Torensma R, Van Vliet SJ, Van Duijnhoven GCF, Adema GJ, Van Kooyk Y, et al. Identification of DC-SIGN, a novel dendritic cell-specific ICAM-3 receptor that supports primary immune responses. Cell (2000) 100:575-85. doi:10.1016/S0092-8674(00)80693-5 pro-virus functions might be natural functions of the CLRs and it is important to further understand these functions and why CLRs require these in inducing immunity. It is likely that these CLRs recognize other pathogens and that the subsequent immune responses require limiting amounts of type I IFN responses or pro-inflammatory cytokines. The elucidation of the mechanisms behind these manipulations is crucial to target CLRs in order to combat viral infections or to prevent viral invasion and is also important to understand inflammatory as well as auto-immune diseases.

\section{AUTHOR CONTRIBUTIONS}

MB, JE, LH, NH, BN, MS: wrote sections of the manuscript, contributed equally. TG: wrote sections of the manuscript, supervision and final responsibility. All authors contributed to manuscript revision, read and approved the submitted version.

\section{ACKNOWLEDGMENTS}

This work was supported by Aidsfonds (2014014), (P-9906), (2012042) and European Research Council, Advanced grant (670424).

13. Feinberg H, Mitchell DA, Drickamer K, Weis WI. Structural basis for selective recognition of oligosaccharides by DC-SIGN and DC-SIGNR. Science (2001) 294:2163-6. doi:10.1126/science.1066371

14. Appelmelk BJ, van Die I, van Vliet SJ, Vandenbroucke-Grauls CMJE, Geijtenbeek TBH, van Kooyk Y. Cutting edge: carbohydrate profiling identifies new pathogens that interact with dendritic cell-specific ICAM3-grabbing nonintegrin on dendritic cells. J Immunol (2003) 170:1635-9. doi:10.4049/jimmunol.170.4.1635

15. Geijtenbeek TB, Kwon DS, Torensma R, van Vliet SJ, van Duijnhoven GC, Middel J, et al. DC-SIGN, a dendritic cell-specific HIV-1-binding protein that enhances trans-infection of T cells. Cell (2000) 100:587-97. doi:10.1016/ S0092-8674(00)80694-7

16. Valladeau J, Ravel O, Dezutter-Dambuyant C, Moore K, Kleijmeer M, Liu Y, et al. Langerin, a novel C-type lectin specific to Langerhans cells, is an endocytic receptor that induces the formation of Birbeck granules. Immunity (2000) 12:71-81. doi:10.1016/S1074-7613(00)80160-0

17. de Witte L, Nabatov A, Pion M, Fluitsma D, de Jong MA, de Gruijl T, et al. Langerin is a natural barrier to HIV-1 transmission by Langerhans cells. Nat Med (2007) 13:367-71. doi:10.1038/nm1541

18. Engering A, Geijtenbeek TBH, van Vliet SJ, Wijers $M$, van Liempt E, Demaurex N, et al. The dendritic cell-specific adhesion receptor DC-SIGN internalizes antigen for presentation to T cells. J Immunol (2002) 168: 2118-26. doi:10.4049/JIMMUNOL.168.5.2118

19. Meyer-Wentrup F, Benitez-Ribas D, Tacken PJ, Punt CJA, Figdor CG, De Vries IJM, et al. Targeting DCIR on human plasmacytoid dendritic cells results in antigen presentation and inhibits IFN-\{alpha\} production. Blood (2008) 111:4245-53. doi:10.1182/blood-2007-03-081398

20. LeibundGut-Landmann S, Groß O, Robinson MJ, Osorio F, Slack EC, Tsoni SV, et al. Syk- and CARD9-dependent coupling of innate immunity to the induction of T helper cells that produce interleukin 17. Nat Immunol (2007) 8:630-8. doi:10.1038/ni1460

21. Gurer C, Strowig T, Brilot F, Pack M, Trumpfheller C, Arrey F, et al. Targeting the nuclear antigen 1 of Epstein-Barr virus to the human endocytic receptor DEC-205 stimulates protective T-cell responses. Blood (2008) 112:1231-9. doi:10.1182/blood-2008-03-148072

22. Pierre P, Turley SJ, Gatti E, Hull M, Meltzer J, Mirza A, et al. Developmental regulation of MHC class II transport in mouse dendritic cells. Nature (1997) 388:787-92. doi:10.1038/42039

23. Bates EE, Fournier N, Garcia E, Valladeau J, Durand I, Pin JJ, et al. APCs express DCIR, a novel C-type lectin surface receptor containing an 
immunoreceptor tyrosine-based inhibitory motif. J Immunol (1999) 163: 1973-83.

24. Mellman I, Steinman RM. Dendritic cells: specialized and regulated antigen processing machines. Cell (2001) 106:255-8. doi:10.1016/S0092-8674(01)00449-4

25. Tel J, Benitez-Ribas D, Hoosemans S, Cambi A, Adema GJ, Figdor CG, et al. DEC-205 mediates antigen uptake and presentation by both resting and activated human plasmacytoid dendritic cells. Eur J Immunol (2011) 41:1014-23. doi:10.1002/eji.201040790

26. Pino M, Erkizia I, Benet S, Erikson E, Fernández-Figueras MT, Guerrero D, et al. HIV-1 immune activation induces Siglec-1 expression and enhances viral trans-infection in blood and tissue myeloid cells. Retrovirology (2015) 12:1-15. doi:10.1186/s12977-015-0160-x

27. Izquierdo-Useros N, Lorizate M,Puertas MC, Rodriguez-Plata MT,ZanggerN, Erikson E, et al. Siglec-1 is a novel dendritic cell receptor that mediates HIV-1 trans-infection through recognition of viral membrane gangliosides. PLoS Biol (2012) 10:e1001448. doi:10.1371/journal.pbio.1001448

28. Lambert AA, Gilbert C, Richard M, Beaulieu AD, Tremblay MJ. The C-type lectin surface receptor DCIR acts as a new attachment factor for HIV-1 in dendritic cells and contributes to trans- and cis-infection pathways. Blood (2008) 112:1299-307. doi:10.1182/blood-2008-01-136473

29. Nguyen DG, Hildreth JE. Involvement of macrophage mannose receptor in the binding and transmission of HIV by macrophages. Eur J Immunol (2003) 33:483-93. doi:10.1002/immu.200310024

30. Simmons G, Reeves JD, Grogan CC, Vandenberghe LH, Baribaud F, Whitbeck JC, et al. DC-SIGN and DC-SIGNR bind ebola glycoproteins and enhance infection of macrophages and endothelial cells. Virology (2003) 305:115-23. doi:10.1006/viro.2002.1730

31. Wiley RD, Gummuluru S. Immature dendritic cell-derived exosomes can mediate HIV-1 trans infection. Proc Natl Acad Sci U S A (2006) 103:738-43. doi:10.1073/pnas.0507995103

32. Wu L, KewalRamani VN. Dendritic-cell interactions with HIV: infection and viral dissemination. Nat Rev Immunol (2006) 6:859-68. doi:10.1038/nri1960

33. Ludwig IS, Lekkerkerker AN, Depla E, Bosman F, Musters RJP, Depraetere S, et al. Hepatitis C virus targets DC-SIGN and L-SIGN to escape lysosomal degradation. J Virol (2004) 78:8322-32. doi:10.1128/JVI.78.15.8322

34. Klimstra WB, Nangle EM, Smith MS, Yurochko AD, Ryman KD. DC-SIGN and L-SIGN can act as attachment receptors for Alphaviruses and distinguish between mosquito cell- and mammalian cell-derived viruses. J Virol (2003) 77:12022-32. doi:10.1128/JVI.77.22.12022-12032.2003

35. Tassaneetrithep B, Burgess TH, Granelli-Piperno A, Trumpfheller C, Finke J, Sun W, et al. DC-SIGN (CD209) mediates dengue virus infection of human dendritic cells. J Exp Med (2003) 197:823-9. doi:10.1084/jem.20021840

36. Davis CW, Nguyen H-Y, Hanna SL, Sánchez MD, Doms RW, Pierson TC. West Nile virus discriminates between DC-SIGN and DC-SIGNR for cellular attachment and infection. J Virol (2006) 80:1290-301. doi:10.1128/ JVI.80.3.1290-1301.2006

37. Alvarez CP, Lasala F, Carrillo J, Muñiz O, Corbí AL, Delgado R. C-type lectins DC-SIGN and L-SIGN mediate cellular entry by ebola virus in cis and in trans. J Virol (2002) 76:6841-4. doi:10.1128/JVI.76.13.6841-6844.2002

38. Halary F, Amara A, Lortat-Jacob H, Messerle M, Delaunay T, Houlès C, et al. Human cytomegalovirus binding to DC-SIGN is required for dendritic cell infection and target cell trans-infection. Immunity (2002) 17:653-64. doi:10.1016/S1074-7613(02)00447-8

39. Wolfson B, Yu JE, Zhou Q. Exosomes may play a crucial role in HIV dendritic cell immunotherapy. Ann Transl Med (2017) 5:337. doi:10.21037/ atm.2017.05.09

40. Ng WC, Londrigan SL, Nasr N, Cunningham AL, Turville S, Brooks AG, et al. The C-type lectin langerin functions as a receptor for attachment and infectious entry of influenza A virus. J Virol (2015) 90:206-21. doi:10.1128/ JVI.01447-15

41. Moris A, Pajot A, Blanchet F, Guivel-benhassine F, Salcedo M, Schwartz O. Dendritic cells and HIV-specific CD4 T cells: HIV antigen presentation, T-cell activation, and viral transfer. Blood (2006) 108:1643-51. doi:10.1182/ blood-2006-02-006361

42. Joffre OP, Segura E, Savina A, Amigorena S. Cross-presentation by dendritic cells. Nat Rev Immunol (2012) 12:557-69. doi:10.1038/nri3254

43. Kovacsovics-Bankowski M, Rock K. A phagosome-to-cytosol pathway for exogenous antigens presented on MHC class I molecules. Science (1995) 267:243-6. doi:10.1126/science.7809629
44. Ackerman AL, Kyritsis C, Tampé R, Cresswell P. Early phagosomes in dendritic cells form a cellular compartment sufficient for cross presentation of exogenous antigens. Proc Natl Acad Sci U S A (2003) 100:12889-94. doi:10.1073/pnas. 1735556100

45. Shen L, Sigal LJ, Boes M, Rock KL. Important role of cathepsin S in generating peptides for TAP-independent MHC class I crosspresentation in vivo. Immunity (2004) 21:155-65. doi:10.1016/J.IMMUNI.2004.07.004

46. Schuette V, Burgdorf S. The ins-and-outs of endosomal antigens for crosspresentation. Curr Opin Immunol (2014) 26:63-8. doi:10.1016/J.COI.2013. 11.001

47. Kurts C, Robinson BWS, Knolle PA. Cross-priming in health and disease. Nat Rev Immunol (2010) 10:403-14. doi:10.1038/nri2780

48. Jongbloed SL, Kassianos AJ, McDonald KJ, Clark GJ, Ju X, Angel CE, et al. Human CD141 + (BDCA-3) + dendritic cells (DCs) represent a unique myeloid DC subset that cross-presents necrotic cell antigens. J Exp Med (2010) 207:1247-60. doi:10.1084/jem.20092140

49. Poulin LF, Salio M, Griessinger E, Anjos-Afonso F, Craciun L, Chen J-L, et al. Characterization of human DNGR-1+ BDCA3+ leukocytes as putative equivalents of mouse CD8alpha+ dendritic cells. JExp Med (2010) 207:1261-71. doi:10.1084/jem.20092618

50. Bachem A, Güttler S, Hartung E, Ebstein F, Schaefer M, Tannert A, et al. Superior antigen cross-presentation and XCR1 expression define human $\mathrm{CD} 11 \mathrm{c}+\mathrm{CD} 141{ }^{+}$cells as homologues of mouse CD8 ${ }^{+}$dendritic cells. J Exp Med (2010) 207:1273-81. doi:10.1084/jem.20100348

51. den Haan JM, Lehar SM, Bevan MJ. CD8(+) but not CD8(-) dendritic cells cross-prime cytotoxic T cells in vivo. J Exp Med (2000) 192:1685-96. doi:10.1084/jem.192.12.1685

52. Dudziak D, Kamphorst AO, Heidkamp GF, Buchholz VR, Trumpfheller C, Yamazaki S, et al. Differential antigen processing by dendritic cell subsets in vivo. Science (2007) 315:107-11. doi:10.1126/science. 1136080

53. Schulz O, Reis e Sousa C. Cross-presentation of cell-associated antigens by CD8alpha+ dendritic cells is attributable to their ability to internalize dead cells. Immunology (2002) 107:183-9. doi:10.1046/j.1365-2567.2002. 01513.x

54. Hanč P, Schulz O, Fischbach H, Martin SR, Kjaer S, Reis e Sousa C. A pHand ionic strength-dependent conformational change in the neck region regulates DNGR-1 function in dendritic cells. EMBO J (2016) 35:2484-97. doi:10.15252/embj.201694695

55. Iborra S, Izquierdo HM, Martínez-López M, Blanco-Menéndez N, Reis e Sousa C, Sancho D. The DC receptor DNGR-1 mediates cross-priming of CTLs during vaccinia virus infection in mice. J Clin Invest (2012) 122: 1628-43. doi:10.1172/JCI60660

56. Zelenay S, Keller AM, Whitney PG, Schraml BU, Deddouche S, Rogers NC, et al. The dendritic cell receptor DNGR-1 controls endocytic handling of necrotic cell antigens to favor cross-priming of CTLs in virus-infected mice. J Clin Invest (2012) 122:1615-27. doi:10.1172/JCI60644

57. Schreibelt G, Klinkenberg LJJ, Cruz LJ, Tacken PJ, Tel J, Kreutz M, et al. The C-type lectin receptor CLEC9A mediates antigen uptake and (cross-) presentation by human blood BDCA3+ myeloid dendritic cells. Blood (2012) 119:2284-92. doi:10.1182/blood-2011-08-373944

58. Klechevsky E, Flamar A-L, Cao Y, Blanck J-P, Liu M, O'Bar A, et al. Crosspriming CD8+ T cells by targeting antigens to human dendritic cells through DCIR. Blood (2010) 116:1685-97. doi:10.1182/blood-2010-01-264960

59. Unger WWJ, van Beelen AJ, Bruijns SC, Joshi M, Fehres CM, van Bloois L, et al. Glycan-modified liposomes boost CD4+ and CD8+ T-cell responses by targeting DC-SIGN on dendritic cells. J Control Release (2012) 160:88-95. doi:10.1016/j.jconrel.2012.02.007

60. García-Vallejo JJ, Ambrosini M, Overbeek A, van Riel WE, Bloem K, Unger WWJ, et al. Multivalent glycopeptide dendrimers for the targeted delivery of antigens to dendritic cells. Mol Immunol (2013) 53:387-97. doi:10.1016/J.MOLIMM.2012.09.012

61. Fehres CM, Duinkerken S, Bruijns SC, Kalay H, van Vliet SJ, Ambrosini M, et al. Langerin-mediated internalization of a modified peptide routes antigens to early endosomes and enhances cross-presentation by human Langerhans cells. Cell Mol Immunol (2017) 14:360-70. doi:10.1038/cmi.2015.87

62. Fehres CM, Kalay H, Bruijns SCM, Musaafir SAM, Ambrosini M, van Bloois L, et al. Cross-presentation through langerin and DC-SIGN targeting requires different formulations of glycan-modified antigens. J Control Release (2015) 203:67-76. doi:10.1016/J.JCONREL.2015.01.040 
63. van der Vlist M, de Witte L, de Vries RD, Litjens M, de Jong MAWP, Fluitsma D, et al. Human Langerhans cells capture measles virus through langerin and present viral antigens to CD4 $+\mathrm{T}$ cells but are incapable of cross-presentation. Eur J Immunol (2011) 41:2619-31. doi:10.1002/eji.201041305

64. Burgdorf S, Schölz C, Kautz A, Tampé R, Kurts C. Spatial and mechanistic separation of cross-presentation and endogenous antigen presentation. Nat Immunol (2008) 9:558-66. doi:10.1038/ni.1601

65. Zehner M, Chasan AI, Schuette V, Embgenbroich M, Quast T, Kolanus W, et al. Mannose receptor polyubiquitination regulates endosomal recruitment of p97 and cytosolic antigen translocation for cross-presentation. Proc Natl Acad Sci U S A (2011) 108:9933-8. doi:10.1073/pnas.1102397108

66. Zehner M, Rauen J, Chasan AI, Embgenbroich M, Camps MG, Kaden S, et al. Intraendosomal flow cytometry: a novel approach to analyze the protein composition of antigen-loaded endosomes. Eur J Immunol (2012) 42:2187-90. doi:10.1002/eji.201142089

67. Zehner M, Burgdorf S. Regulation of antigen transport into the cytosol for cross-presentation by ubiquitination of the mannose receptor. $\mathrm{Mol}$ Immunol (2013) 55:146-8. doi:10.1016/j.molimm.2012.10.010

68. Andersen BM, Ohlfest JR. Increasing the efficacy of tumor cell vaccines by enhancing cross priming. Cancer Lett (2012) 325:155-64. doi:10.1016/ j.canlet.2012.07.012

69. van Kooyk Y, Unger WWJ, Fehres CM, Kalay H, García-Vallejo JJ. Glycanbased DC-SIGN targeting vaccines to enhance antigen cross-presentation. Mol Immunol (2013) 55:143-5. doi:10.1016/J.MOLIMM.2012.10.031

70. Goujon C, Moncorgé O, Bauby H, Doyle T, Ward CC, Schaller T, et al. Human MX2 is an interferon-induced post-entry inhibitor of HIV-1 infection. Nature (2013) 502:559-62. doi:10.1038/nature12542

71. Kane M, Yadav SS, Bitzegeio J, Kutluay SB, Zang T, Wilson SJ, et al. MX2 is an interferon-induced inhibitor of HIV-1 infection. Nature (2013) 502:563-6. doi:10.1038/nature 12653

72. Yan N, Chen ZJ. Intrinsic antiviral immunity. Nat Immunol (2012) 13:214-22. doi:10.1038/ni.2229

73. Sandler NG, Bosinger SE, Estes JD, Zhu RTR, Tharp GK, Boritz E, et al. Type I interferon responses in rhesus macaques prevent SIV infection and slow disease progression. Nature (2014) 511:601-5. doi:10.1038/nature13554

74. Geijtenbeek TBH, Gringhuis SI. Signalling through C-type lectin receptors: shaping immune responses. Nat Rev Immunol (2009) 9:465-79. doi:10.1038/ nri2569

75. Monteiro JT, Lepenies B. Myeloid C-type lectin receptors in viral recognition and antiviral immunity. Viruses (2017) 9:59. doi:10.3390/v9030059

76. Thompson MR, Kaminski JJ, Kurt-Jones EA, Fitzgerald KA. Pattern recognition receptors and the innate immune response to viral infection. Viruses (2011) 3:920-40. doi:10.3390/v3060920

77. Lester SN, Li K. Toll-like receptors in antiviral innate immunity. J Mol Biol (2014) 426:1246-64. doi:10.1016/j.jmb.2013.11.024

78. McNab F, Mayer-Barber K, Sher A, Wack A, O'Garra A. Type I interferons in infectious disease. Nat Rev Immunol (2015) 15:87-103. doi:10.1038/nri3787

79. Pestka S, Krause CD, Walter MR. Interferons, interferon-like cytokines, and their receptors. Immunol Rev (2004) 202:8-32. doi:10.1111/j.0105-2896. 2004.00204.x

80. Sato M, Tanaka N, Hata N, Oda E, Taniguchi T. Involvement of the IRF family transcription factor IRF-3 in virus-induced activation of the IFN-beta gene. FEBS Lett (1998) 425:112-6. doi:10.1016/S0014-5793(98)00210-5

81. Marie I, Durbin JE, Levy DE. Differential viral induction of distinct interferon-alpha genes by positive feedback through interferon regulatory factor-7. EMBO J (1998) 17:6660-9. doi:10.1093/emboj/17.22.6660

82. Honda K, Takaoka A, Taniguchi T. Type I inteferon gene induction by the interferon regulatory factor family of transcription factors. Immunity (2006) 25:349-60. doi:10.1016/j.immuni.2006.08.009

83. Tamura T, Yanai H, Savitsky D, Taniguchi T. The IRF family transcription factors in immunity and oncogenesis. Annu Rev Immunol (2008) 26:535-84. doi:10.1146/annurev.immunol.26.021607.090400

84. de Veer MJ, Holko M, Frevel M, Walker E, Der S, Paranjape JM, et al. Functional classification of interferon-stimulated genes identified using microarrays. J Leukoc Biol (2001) 69:912-20. doi:10.1189/jlb.69.6.912

85. Coccia EM. IFN regulation and functions in myeloid dendritic cells. Cytokine Growth Factor Rev (2008) 19:21-32. doi:10.1016/j.cytogfr.2007.10.005

86. Richard M, Thibault N, Veilleux P, Gareau-Pagé G, Beaulieu AD. Granulocyte macrophage-colony stimulating factor reduces the affinity of SHP-2 for the
ITIM of CLECSF6 in neutrophils: a new mechanism of action for SHP-2. Mol Immunol (2006) 43:1716-21. doi:10.1016/j.molimm.2005.10.006

87. Meyer-Wentrup F, Cambi A, Joosten B, Looman MW, de Vries IJM, Figdor CG, et al. DCIR is endocytosed into human dendritic cells and inhibits TLR8mediated cytokine production. J Leukoc Biol (2008) 85:518-25. doi:10.1189/ jlb.0608352

88. Zhao X, Shen Y, Hu W, Chen J, Wu T, Sun X, et al. DCIR negatively regulates CpG-ODN-induced IL-1 $\beta$ and IL-6 production. Mol Immunol (2015) 68:641-7. doi:10.1016/j.molimm.2015.10.007

89. Troegeler A, Mercier I, Cougoule C, Pietretti D, Colom A, Duval C, et al. C-type lectin receptor DCIR modulates immunity to tuberculosis by sustaining type I interferon signaling in dendritic cells. Proc Natl Acad Sci U S A (2017) 114:E540-9. doi:10.1073/pnas.1613254114

90. Long KM, Whitmore AC, Ferris MT, Sempowski GD, McGee C, Trollinger B, et al. Dendritic Cell immunoreceptor regulates chikungunya virus pathogenesis in mice. J Virol (2013) 87:5697-706. doi:10.1128/JVI.01611-12

91. Lambert AA, Imbeault ML, Gilbert C, Tremblay MJ. HIV-1 induces DCIR expression in CD4+ T cells. PLoS Pathog (2010) 6:e1001188. doi:10.1371/ journal.ppat.1001188

92. Dzionek A, Fuchs A, Schmidt P, Cremer S, Zysk M, Miltenyi S, et al. BDCA-2, BDCA-3, and BDCA-4: three markers for distinct subsets of dendritic cells in human peripheral blood. J Immunol (2000) 165:6037-46. doi:10.4049/ jimmunol.165.11.6037

93. Dzionek A, Sohma Y, Nagafune J, Cella M, Colonna M, Facchetti F, et al. BDCA-2, a novel plasmacytoid dendritic cell-specific type II C-type lectin mediates antigen capture and is a potent inhibitor of interferon alpha/ beta induction. JExp Med (2001) 194:1823-34. doi:10.1084/jem.194. 12.1823

94. Dzionek A, Inagaki Y, Okawa K, Nagafune J, Röck J, Sohma Y, et al. Plasmacytoid dendritic cells: from specific surface markers to specific cellular functions. Hum Immunol (2002) 63:1133-48. doi:10.1016/S0198-8859 (02)00752-8

95. Kanazawa N, Tashiro K, Inaba K, Miyachi Y. Dendritic cell immunoactivating receptor, a novel $\mathrm{C}$-type lectin immunoreceptor, acts as an activating receptor through association with Fc receptor $\gamma$ chain. J Biol Chem (2003) 278:32645-52. doi:10.1074/jbc.M304226200

96. Cao W, Zhang L, Rosen DB, Bover L, Watanabe G, Bao M, et al. BDCA2/ FceRI $\gamma$ complex signals through a novel BCR-like pathway in human plasmacytoid dendritic cells. PLoS Biol (2007) 5:2190-200. doi:10.1371/journal. pbio. 0050248

97. Florentin J, Aouar B, Dental C, Thumann C, Firaguay G, Gondois-Rey F, et al. HCV glycoprotein E2 is a novel BDCA-2 ligand and acts as an inhibitor of IFN production by plasmacytoid dendritic cells. Blood (2012) 120:4544-51. doi:10.1182/blood-2012-02-413286

98. Beatty PR, Puerta-Guardo H, Killingbeck SS, Glasner DR, Hopkins K, Harris E. Dengue virus NS1 triggers endothelial permeability and vascular leak that is prevented by NS1 vaccination. Sci Transl Med (2015) 7:304ra141. doi:10.1126/scitranslmed.aaa3787

99. Cox J, Mota J, Sukupolvi-Petty S, Diamond MS, Rico-Hesse R. Mosquito bite delivery of dengue virus enhances immunogenicity and pathogenesis in humanized mice. J Virol (2012) 86:7637-49. doi:10.1128/JVI.00534-12

100. Schaeffer E, Flacher V, Papageorgiou V, Decossas M, Fauny JD, Krämer M, et al. Dermal CD14 + dendritic cell and macrophage infection by dengue virus is stimulated by interleukin-4. J Invest Dermatol (2015) 135:1743-51. doi:10.1038/jid.2014.525

101. Arboleda Alzate JF, Rodenhuis-Zybert IA, Hernández JC, Smit JM, UrcuquiInchima S. Human macrophages differentiated in the presence of vitamin D3restrict dengue virus infection and innate responses by downregulating mannose receptor expression. PLoS Negl Trop Dis (2017) 11:e0005904. doi:10.1371/journal.pntd.0005904

102. Wu MF, Chen ST, Hsieh SL. Distinct regulation of dengue virus-induced inflammasome activation in human macrophage subsets. J Biomed Sci (2013) 20:1-9. doi:10.1186/1423-0127-20-36

103. Chen ST, Liu RS, Wu MF, Lin YL, Chen SY, Tan DTW, et al. CLEC5A regulates Japanese encephalitis virus-induced neuroinflammation and lethality. PLoS Pathog (2012) 8:e1002655. doi:10.1371/journal.ppat.1002655

104. Viswanathan K, Chandrasekaran A, Srinivasan A, Raman R, Sasisekharan V, Sasisekharan R. Glycans as receptors for influenza pathogenesis. Glycoconj J (2010) 27:561-70. doi:10.1007/s10719-010-9303-4 
105. Teng O, Chen S, Hsu T, Sia S, Cole S, Valkenburg S, et al. CLEC5A-mediated enhancement of the inflammatory response in myeloid cells contributes to influenza virus pathogenicity in vivo. J Virol (2017) 91:1-16. doi:10.1128/ JVI.01813-16

106. Heil F, Hemmi H, Hochrein H, Ampenberger F, Kirschning C, Akira S, et al. Species-specific recognition of single-stranded RNA via toll-like receptor 7 and 8. Science (2004) 303:1526-9. doi:10.1126/science.1093620

107. Beignon A, Mckenna K, Skoberne M, Manches O, Dasilva I, Kavanagh DG, et al. Endocytosis of HIV-1 activates plasmacytoid dendritic cells via tolllike receptor-viral RNA interactions. J Clin Invest (2005) 115:3265-75. doi:10.1172/JCI26032

108. Gringhuis SI, van der Vlist M, van den Berg LM, den Dunnen J, Litjens M, Geijtenbeek TBH. HIV-1 exploits innate signaling by TLR8 and DC-SIGN for productive infection of dendritic cells. Nat Immunol (2010) 11:419-26. doi:10.1038/ni.1858

109. Gringhuis SI, Hertoghs N, Kaptein TM, Zijlstra-Willems EM, SarramiFooroshani R, Sprokholt JK, et al. HIV-1 blocks the signaling adaptor MAVS to evade antiviral host defense after sensing of abortive HIV-1 RNA by the host helicase DDX3. Nat Immunol (2017) 18:225-35. doi:10.1038/ ni.3647

110. Mesman AW, Zijlstra-Willems EM, Kaptein TM, De Swart RL, Davis ME, Ludlow $\mathrm{M}$, et al. Measles virus suppresses RIG-I-like receptor activation in dendritic cells via DC-SIGN-mediated inhibition of PP1 phosphatases. Cell Host Microbe (2014) 16:31-42. doi:10.1016/j.chom.2014.06.008

111. den Dunnen J, Gringhuis SI, Geijtenbeek TBH. Dusting the sugar fingerprint: C-type lectin signaling in adaptive immunity. Immunol Lett (2010) 128:12-6. doi:10.1016/j.imlet.2009.09.008

112. Gringhuis SI, Kaptein TM, Wevers BA, Van Der Vlist M, Klaver EJ, Van Die I, et al. Fucose-based PAMPs prime dendritic cells for follicular T helper cell polarization via DC-SIGN-dependent IL-27 production. Nat Commun (2014) 5:5074. doi:10.1038/ncomms6074

113. Crotty S. T follicular helper cell differentiation, function, and roles in disease. Immunity (2014) 41:529-42. doi:10.1016/j.immuni.2014.10.004

114. Geijtenbeek TBH, Gringhuis SI. C-type lectin receptors in the control of T helper cell differentiation. Nat Rev Immunol (2016) 16:433-48. doi:10.1038/ nri.2016.55

115. Švajger U, Anderluh M, Jeras M, Obermajer N. C-type lectin DC-SIGN: an adhesion, signalling and antigen-uptake molecule that guides dendritic cells in immunity. Cell Signal (2010) 22:1397-405. doi:10.1016/j.cellsig.2010. 03.018

116. van Kooyk Y. C-type lectins on dendritic cells: key modulators for the induction of immune responses. Biochem Soc Trans (2008) 36:1478-81. doi:10.1042/BST0361478

117. Gringhuis SI, den Dunnen J, Litjens M, van der Vlist M, Geijtenbeek TBH. Carbohydrate-specific signaling through the DC-SIGN signalosome tailors immunity to Mycobacterium tuberculosis, HIV-1 and Helicobacter pylori. Nat Immunol (2009) 10:1081-8. doi:10.1038/ni.1778

118. Gringhuis SI, Kaptein TM, Wevers BA, Mesman AW, Geijtenbeek TBH. Fucose-specific DC-SIGN signalling directs T helper cell type-2 responses via IKKe-and CYLD-dependent Bcl3 activation. Nat Commun (2014) 5:3898. doi:10.1038/ncomms4898

119. Gringhuis SI, den Dunnen J, Litjens M, van het Hof B, van Kooyk Y, Geijtenbeek TBH. C-type lectin DC-SIGN modulates toll-like receptor signaling via Raf-1 kinase-dependent acetylation of transcription factor NF-kappaB. Immunity (2007) 26:605-16. doi:10.1016/j.immuni.2007.03.012

120. Stansell E, Desrosiers RC. Fundamental difference in the content of high-mannose carbohydrate in the HIV-1 and HIV-2 lineages. J Virol (2010) 84:8998-9009. doi:10.1128/JVI.00996-10

121. Salazar F, Hall L, Negm OH, Awuah D, Tighe PJ, Shakib F, et al. The mannose receptor negatively modulates the Toll-like receptor 4-aryl hydrocarbon receptor-indoleamine 2,3-dioxygenase axis in dendritic cells affecting $\mathrm{T}$ helper cell polarization. J Allergy Clin Immunol (2016) 137:1841-51.e1. doi:10.1016/ j.jaci.2015.10.033

122. Chen CH, Floyd H, Olson NE, Magaletti D, Li C, Draves K, et al. Dendriticcell-associated C-type lectin 2 (DCAL-2) alters dendritic-cell maturation and cytokine production. Blood (2006) 107:1459-67. doi:10.1182/ blood-2005-08-3264

123. Merle NS, Noe R, Halbwachs-Mecarelli L, Fremeaux-Bacchi V, Roumenina LT. Complement system part II: role in immunity. Front Immunol (2015) 6:257. doi:10.3389/fimmu.2015.00257
124. Fujita T. Evolution of the lectin-complement pathway and its role in innate immunity. Nat Rev Immunol (2002) 2:346-53. doi:10.1038/nri800

125. Dahl MR, Thiel S, Matsushita M, Fujita T, Willis AC, Christensen T, et al. MASP-3 and its association with distinct complexes of the mannanbinding lectin complement activation pathway. Immunity (2001) 15:127-35. doi:10.1016/S1074-7613(01)00161-3

126. Kawasaki N, Kawasaki T, Yamashina I. A serum lectin (mannan-binding protein) has complement-dependent bactericidal activity. J Biochem (1989) 106:483-9. doi:10.1093/oxfordjournals.jbchem.a122878

127. Neth O, Jack DL, Johnson M, Klein NJ, Turner MW. Enhancement of complement activation and opsonophagocytosis by complexes of mannose-binding lectin with mannose-binding lectin-associated serine protease after binding to Staphylococcus aureus. JImmunol (2002) 169:4430-6. doi:10.4049/ jimmunol.169.8.4430

128. Ezekowitz RA, Kuhlman M, Groopman JE, Byrn RA. A human serum mannose-binding protein inhibits in vitro infection by the human immunodeficiency virus. J Exp Med (1989) 169:185-96. doi:10.1084/jem.169.1.185

129. Saifuddin M, Hart ML, Gewurz H, Zhang Y, Spear GT. Interaction of mannose-binding lectin with primary isolates of human immunodeficiency virus type 1. J Gen Virol (2000) 81:949-55. doi:10.1099/0022-1317-81-4-949

130. Yu Q, Yu R, Qin X. The good and evil of complement activation in HIV-1 infection. Cell Mol Immunol (2010) 7:334-40. doi:10.1038/cmi.2010.8

131. Posch W, Lass-Flörl C, Wilflingseder D. Role of dendritic cell subsets on HIV-specific immunity. In: Saxena SK, editor. Current Perspectives in HIV Infection. InTech (2013). Available from: https:// www.intechopen.com/books/current-perspectives-in-hiv-infection/ role-of-dendritic-cell-subsets-on-hiv-specific-immunity

132. Luo Y, Yu H, Peterlin BM. Cellular protein modulates effects of human immunodeficiency virus type 1 Rev. J Virol (1994) 68:3850-6.

133. Szabó J, Cervenák L, Tóth FD, Prohászka Z, Horváth L, Kerekes K, et al. Soluble gC1q-R/p33, a cell protein that binds to the globular "heads" of C1q, effectively inhibits the growth of HIV-1 strains in cell cultures. Clin Immunol (2001) 99:222-31. doi:10.1006/clim.2001.5013

134. Fausther-Bovendo PH, Vieillard V, Sagan S, Bismuth G, Debré P. Hiv gp41 engages gclqr on $\mathrm{cd} 4+\mathrm{t}$ cells to induce the expression of an nk ligand through the pip3/h2o2. PLoS Pathog (2010) 6:1-14. doi:10.1371/journal. ppat. 1000975

135. Yu L, Loewenstein PM, Zhang Z, Green M. In vitro interaction of the human immunodeficiency virus type 1 Tat transactivator and the general transcription factor TFIIB with the cellular protein TAP. J Virol (1995) 69:3017-23.

136. Thielens NM, Bally IM, Ebenbichler CF, Dierich MP, Arlaud GJ. Further characterization of the interaction between the $\mathrm{Clq}$ subcomponent of human $\mathrm{C} 1$ and the transmembrane envelope glycoprotein gp41 of HIV-1. J Immunol (1993) 151:6583-92.

137. Quinkal I, Hernandez JF, Chevallier S, Arlaud GJ, Vernet T. Mapping of the interaction between the immunodominant loop of the ectodomain of HIV-1 gp41 and human complement protein c1q. Eur J Biochem (1999) 265:656-63. doi:10.1046/j.1432-1327.1999.00757.x

138. Ji X, Gewurz H, Spear GT. Mannose binding lectin (MBL) and HIV. Mol Immunol (2005) 42:145-52. doi:10.1016/J.MOLIMM.2004.06.015

139. Jiang H, Hester G, Liao L, Montefiori DC, Frank MM. Mechanisms by which HIV envelope minimizes immunogenicity. Immunol Res (2011) 49:147-58. doi:10.1007/s12026-010-8178-6

140. Thielens NM, Tacnet-Delorme P, Arlaud GJ. Interaction of C1q and mannan-binding lectin with viruses. Immunobiology (2002) 205:563-74. doi:10.1078/0171-2985-00155

141. Bouhlal H, Chomont N, Haeffner-Cavaillon N, Kazatchkine MD, Belec L, Hocini H. Opsonization of HIV-1 by semen complement enhances infection of human epithelial cells. J Immunol (2002) 169:3301-6. doi:10.4049/ jimmunol.169.6.3301

142. Pruenster M, Wilflingseder D, Bánki Z, Ammann CG, Muellauer B, Meyer M, et al. C-type lectin-independent interaction of complement opsonized HIV with monocyte-derived dendritic cells. Eur J Immunol (2005) 35:2691-8. doi:10.1002/eji.200425940

143. Geijtenbeek TBH, van Kooyk Y. DC-SIGN: a novel HIV receptor on DCs that mediates HIV-1 transmission. Curr Top Microbiol Immunol (2003) 276:31-54. doi:10.1007/978-3-662-06508-2_2

144. Bajtay Z, Speth C, Erdei A, Dierich MP. Cutting edge: productive HIV-1 infection of dendritic cells via complement receptor type 3 (CR3, CD11b/ CD18). J Immunol (2004) 173:4775-8. doi:10.4049/jimmunol.173.8.4775 
145. Kang YS, Do Y, Lee HK, Park SH, Cheong C, Lynch RM, et al. A dominant complement fixation pathway for pneumococcal polysaccharides initiated by SIGN-R1 interacting with C1q. Cell (2006) 125:47-58. doi:10.1016/j.cell. 2006.01.046

146. Kawauchi Y, Igarashi M, Kojima N. C-type lectin receptor SIGNR1 expressed on peritoneal phagocytic cells with an immature dendritic celllike phenotype is involved in uptake of oligomannose-coated liposomes and subsequent cell maturation. Cell Immunol (2014) 287:121-8. doi:10.1016/ j.cellimm.2014.01.004

147. Posch W, Steger M, Knackmuss U, Blatzer M, Baldauf HM, Doppler W, et al. Complement-opsonized HIV-1 overcomes restriction in dendritic cells. PLoS Pathog (2015) 11:e1005005. doi:10.1371/journal.ppat.1005005
Conflict of Interest Statement: The authors declare that the research was conducted in the absence of any commercial or financial relationships that could be construed as a potential conflict of interest.

Copyright (C) 2018 Bermejo-Jambrina, Eder, Helgers, Hertoghs, Nijmeijer, Stunnenberg and Geijtenbeek. This is an open-access article distributed under the terms of the Creative Commons Attribution License (CC BY). The use, distribution or reproduction in other forums is permitted, provided the original author(s) and the copyright owner are credited and that the original publication in this journal is cited, in accordance with accepted academic practice. No use, distribution or reproduction is permitted which does not comply with these terms. 